\title{
Quality of life of caregivers with children having congenital heart disease awaiting cardiac surgery at the Lady Ridgeway Hospital for Children, Colombo, Sri Lanka
}

\author{
*Pavithra Harshani Warnakulasooriya ${ }^{1}$, Kaushalya Kasturiaratchi ${ }^{2}$
}

Sri Lanka Journal of Child Health, 2020: 49(1): 17-22

\begin{abstract}
Introduction: Congenital heart disease (CHD) has an accepted estimated prevalence of around 8$12 / 1000$ live births

Objectives: To determine the level of quality of life (QOL) of primary caregivers whose children with CHD are attending cardiology clinics in Lady Ridgeway Hospital (LRH), Colombo, awaiting cardiac surgery.
\end{abstract}

Method: This study was carried out as an institution-based descriptive cross-sectional study, of 422 caregivers, through consecutive convenient sampling method over a two month period at the cardiology unit of Lady Ridgeway Hospital. An interviewer administered questionnaire was utilized to obtain data and the QOL was assessed by WHOQOL-BREF questionnaire which was validated in Sri Lanka and consists of 26 questions. WHOQOL-BREF is an abbreviated generic QOL scale developed through the World Health Organization. Question one is the individual's overall perception of QOL, and question two is individual's overall perception of health. Rest of the 24 questions are in four domains, physical health, psychological health, social relationship and environmental relationship. Data extraction sheet was used to get clinic records. Univariate analysis and regression were done to detect association.

Results: Of the caregivers $89.3 \%$ were mothers, $51 \%$ were in the 30 to 39 -year age group, and $75 \%$ were unemployed. Overall perception of QOL and

${ }^{1}$ Post Graduate Trainee in Community Medicine,
${ }^{2}$ Consultant Community Physician, Monitoring and
Evaluation Unit, Family Health Bureau, Ministry
of Health, De Saram Place, Colombo 10.
${ }^{*}$ Correspondence: pharshani@gmail.com

D https://orcid.org/0000-0003-0878-6063

(Received on 16 April 2019: Accepted after revision on 24 June 2019)

The authors declare that there are no conflicts of interest

Personal funding was used for the project.

Open Access Article published under the

Commons Attribution CC-BY (c) (i) License overall perception of their health had means of 2.48 (SD 0.66) and 2.48 (SD 0.67) respectively. The highest mean score was recorded in social relationship domain and was 57.15 (SD 12.87), whilst the lowest mean score was recorded in psychological domain and was 39.38 (SD 11.93). Except for social relationship domain, all other domain scores were less than $50 \%$ of QOL.

Conclusions: Caregivers of children with CHD attending cardiology clinics in LRH, Colombo and awaiting cardiac surgery are experiencing a low QOL. The QOL was associated with age of the caregiver, educational level, marital status, number of children, income, type of heart disease, and postponement of surgery. QOL had no significant association with gender, religion, employment status or presence of co-morbidities.

DOI: http://dx.doi.org/10.4038/sljch.v49i1.8892

(Key words: Quality of life, primary caregivers, children with congenital heart disease awaiting cardiac surgery)

\section{Introduction}

Congenital heart disease (CHD) has an accepted estimated prevalence around 8-12/1000 live births ${ }^{1}$. Common severe congenital anomalies are heart defects, neural tube defects and Down syndrome ${ }^{2}$. From 1960-1994 in the USA, birth defect specific infant mortality decreased by $53 \%$ but congenital anomalies still remained the leading cause of infant deaths ${ }^{3}$. Unlike in the West, CHD is not familiar territory for researchers in Sri Lanka. Therefore, it is extremely difficult to obtain the complete Sri Lankan scenario of $\mathrm{CHD}^{4}$. Other leading causes of death for children in the age group 0 to 4 years are congenital malformations, deformations and chromosomal abnormalities which together account for $24 \%$ of total deaths in that age group ${ }^{5}$. As CHD is the commonest congenital anomaly, it contributes significantly to neonatal and infant mortality in Sri Lanka ${ }^{4}$. The limited data available show that numbers in Sri Lanka are compatible with world prevalence of $\mathrm{CHD}^{4}$. According to the WHO definition, quality of life (QOL) is an individual's perception of his position in life, in the context of the culture and value system, in which he lives and in relation to his goals, expectations, standards, and concerns ${ }^{6}$. QOL is also an essential 
outcome measure in health economic evaluations, which are fundamental in allocating health care resources?.

Lady Ridgeway Hospital (LRH) is the only tertiary care referral centre for children with CHD in Sri Lanka. A considerable number of children need surgical or catheter based treatment within first year of life. Annually, more than thousand cardiac surgeries and cardiac catheterizations are done in LRH, which is about $55 \%$ of the annual need for cardiac intervention. There are also very few government and private hospitals equipped to perform such a procedure in Sri Lanka ${ }^{8}$. According to hospital data, over 3000 children are born with CHD in Sri Lanka per year. Of this number, the hospital can only treat 1700 children annually. Over $40 \%$ of these children do not have appropriate access to early intervention and are compelled to await their turn ${ }^{9}$. Around 1000 children with CHD are waitlisted for treatment annually, due to the hospital's limited capacity. Most of them have to wait for months or years, due to resource constraints. With the passage of time, chances of recovery of these children lessen and some may even die of the illness before their turn for surgery 9 . Over $90 \%$ of these CHDs could be cured with timely, and proper treatment. Even though the cost of each surgery is high (around RS. 100,000) for the medicine and consumables when these children are treated on time, they become normal and productive citizens. If they do not receive timely and proper treatment these children are a huge burden on their families and this will affect their QOL further ${ }^{8}$. There are not enough studies published in Sri Lanka on children with CHD and these are not sufficient to provide a satisfactory image of the burden to their families. Therefore, this study will explore an important territory of the problems faced by caregivers of children with CHDs awaiting surgery in Sri Lankan context.

\section{Objectives}

To determine the level of quality of life (QOL) of primary caregivers whose children with $\mathrm{CHD}$ are attending cardiology clinics in LRH, Colombo, awaiting cardiac surgery.

The specific objectives are to:

- To determine the level of QOL of the primary caregivers whose children with CHD are attending cardiology clinics in LRH, Colombo, awaiting cardiac surgery.

- To describe the factors associated with the QOL of the primary caregivers.

\section{Method}

A cross sectional descriptive study was carried out in the cardiology clinics at LRH, Colombo. Data were collected from August 2017 to September
2017. Study population comprised primary caregivers of children with diagnosed CHD followed up in the cardiology clinics at LRH for at least six months awaiting cardiac surgery. Primary caregivers who had siblings with chronic illnesses, primary caregivers who had chronic illnesses and caregivers accompanying the patient on the data collection day who were not the regular caregiver, were excluded to reduce selection bias.

The sample size ${ }^{10}$ was 426 . Convenient consecutive sampling technique was used. A structured pretested interviewer administered questionnaire, inclusive of WHO, QOL-BREFF Tool, which has been translated to the Sinhala language by the Field Centre for WHOQOL, University of Ruhuna ${ }^{11}$, and the data extraction sheet were used. BREFF tool validated in Sri Lanka showed good convergent and discriminant validity ${ }^{12}$. It consists of 26 questions. Question one targeted an individual's overall perception of QOL and his or her life, and question two targeted an individual's overall perception of his/her health. The remaining 24 questions were categorized into four domains, namely, physical health, psychological health, social relationship, and environmental relationship ${ }^{13}$. To minimize inter-observer variations only one pre-intern medical officer was used as a data collector in addition to the principal investigator.

The data processing and analysis were done by the principal investigator using the Statistical Package of Social Sciences (SPSS) version 21. Data related to QOL were also entered, according to instructions and guidelines provided by the WHO QOL group to obtain total domain scores. Data analysis for inferential statistical to determine the association between socio-economic factors and child factors with levels of the four domains of QOL were considered as dependent variables, while the associated factors were considered as independent variables. Normal distribution was confirmed by normality test and Q-Q plots for scores of the tool. Student t-test was used for the bivariate analysis. A " $p$ " value of less than 0.05 was considered as statistically significant. Regression analysis was used to exclude the confounders.

Ethical clearance to conduct the study was obtained from Ethics Review Committee of the Post Graduate Institute of Medicine. Simultaneously approval was obtained from Ethics Review Committee of LRH.

\section{Results}

Response rate was 99\%. Sample comprised 422 caregivers of children with diagnosed CHD awaiting cardiac surgery. The demographic characteristics of caregivers are shown in Table 1. 
Table 1: Demographic characteristics of caregivers $(n=422)$

\begin{tabular}{|c|c|c|c|}
\hline Characteristic & Number (\%) & Characteristic & Number (\%) \\
\hline $\begin{array}{l}\text { Gender } \\
\text { Female } \\
\text { Male }\end{array}$ & $\begin{array}{c}382(90.5) \\
40(09.5)\end{array}$ & $\begin{array}{l}\text { Age group (years) } \\
<20 \\
20-29 \\
30-39 \\
40-49 \\
50-59 \\
\end{array}$ & $\begin{array}{c}04(0.9) \\
117(27.7) \\
217(51.4) \\
77(18.2) \\
07(01.7) \\
\end{array}$ \\
\hline $\begin{array}{l}\text { Primary caregiver } \\
\text { Mother } \\
\text { Father } \\
\text { Others }\end{array}$ & $\begin{array}{l}377(89.0) \\
39(09.3) \\
06(01.7)\end{array}$ & $\begin{array}{l}\text { Educational level } \\
\text { No formal schooling } \\
\text { Primary (grades 1-5) } \\
\text { Grades 6-11 } \\
\text { Passed GCE O/L } \\
\text { Follow GCE A/L } \\
\text { Passed GCE A/L } \\
\text { Vocational training } \\
\text { Higher education }\end{array}$ & $\begin{array}{c}02(0.4) \\
26(06.1) \\
147(34.8) \\
107(25.4) \\
77(18.2) \\
36(08.5) \\
09(02.3) \\
18(04.2)\end{array}$ \\
\hline $\begin{array}{l}\text { Ethnicity } \\
\text { Sinhalese } \\
\text { Others }\end{array}$ & $\begin{array}{c}342(81.0) \\
80(19.0)\end{array}$ & $\begin{array}{l}\text { Number of children } \\
\text { One } \\
\text { Two } \\
\text { Three } \\
\text { Four } \\
\text { More than four }\end{array}$ & $\begin{array}{c}114(27.0) \\
176(41.7) \\
110(26.1) \\
18(04.3) \\
04(0.9)\end{array}$ \\
\hline $\begin{array}{l}\text { Marital status } \\
\text { Married } \\
\text { Widow } \\
\text { Separated } \\
\text { Divorced } \\
\text { Unmarried }\end{array}$ & $\begin{array}{c}410(97.2) \\
0 \\
08(01.9) \\
04(0.9) \\
0\end{array}$ & $\begin{array}{l}\text { Employment status } \\
\text { Employed } \\
\text { Unemployed }\end{array}$ & $\begin{array}{l}105(24.9) \\
317(75.1)\end{array}$ \\
\hline $\begin{array}{l}\text { Religion } \\
\text { Buddhism } \\
\text { Others }\end{array}$ & $\begin{array}{l}320(75.8) \\
102(24.2)\end{array}$ & $\begin{array}{l}\text { Income (Rupees) } \\
<10,000 \\
10,000-20,000 \\
20,001-30,000 \\
30,001-50,000 \\
>50,000\end{array}$ & $\begin{array}{c}22(05.2) \\
115(27.3) \\
110(26.1) \\
125(29.6) \\
50(11.8)\end{array}$ \\
\hline
\end{tabular}

Majority of primary caregivers were mothers in the age group 30 to 39 years. Of the primary caregivers $59 \%$ had an income less than Rs. 30,000 and 75\% were unemployed. The surgery date was given only in $131(31 \%)$ cases so that $69 \%$ were in the waiting list without being given the date of surgery.
Furthermore, surgery was postponed in 124 $(23.4 \%)$ cases.

The distribution of facet and domain scores of patients in relation to QOL is shown in Table 2.

Table 2: Distribution of facet and domain scores of patients in relation to the quality of life

\begin{tabular}{|l|c|c|c|c|c|c|}
\hline & Mean & SD & SE of Mean & Minimum & Maximum & Range \\
\hline Facet & & & & & & \\
Q1 - Overall QOL & 2.48 & 0.66 & 0.03 & 1 & 4 & 3 \\
Q2 - Health status & 2.48 & 0.66 & 0.03 & 1 & 4 & 3 \\
\hline Domain & & & & & & \\
Physical health & 39.52 & 10.78 & 0.08 & 13 & 69 & 56 \\
Psychological & 39.38 & 11.93 & 0.06 & 6 & 69 & 63 \\
Social relationship & 57.15 & 12.87 & 0.1 & 6 & 75 & 69 \\
Environmental & 43.92 & 8.75 & 0.07 & 19 & 69 & 50 \\
\hline
\end{tabular}

$S D=$ standard deviation $S E$ of mean $=$ Standard error of mean difference

The highest mean score of QOL, which was 57.15, was recorded in the social relationship domain and the lowest, which was 39.38, was recorded in the psychological domain. Excepting social relationship domain, all other domain scores were less than $50 \%$ of QOL (Table 2).

The association of sociodemographic factors and QOL is shown in Table 3. 
Table 3: Association of sociodemographic factors and quality of life $(n=422)$

\begin{tabular}{|l|c|c|c|c|c|c|c|c|c|}
\hline Variable & $\mathbf{n}$ & $\begin{array}{c}\text { Physical } \\
\text { health } \\
\text { Mean (SD) }\end{array}$ & $\begin{array}{c}\mathbf{p} \\
\mathbf{p}\end{array}$ & $\begin{array}{c}\text { Psychological } \\
\text { health } \\
\text { Mean (SD) }\end{array}$ & $\begin{array}{c}\mathbf{t} \\
\mathbf{p}\end{array}$ & $\begin{array}{c}\text { Social } \\
\text { health } \\
\text { Mean (SD) }\end{array}$ & $\begin{array}{c}\mathbf{t} \\
\mathbf{p}\end{array}$ & $\begin{array}{c}\text { Environmental } \\
\text { health } \\
\text { Mean (SD) }\end{array}$ & $\begin{array}{c}\mathbf{t} \\
\mathbf{p}\end{array}$ \\
\hline Married & 410 & $39.3(10.7)$ & 1.589 & $40.9(10.4)$ & 5.032 & $57.4(12.7)$ & 2.876 & $44.2(08.5)$ & 2.633 \\
Unmarried & 12 & $34.5(11.1)$ & 0.113 & $34.9(10.6)$ & $<0.001$ & $46.9(18.3)$ & 0.005 & $35.0(11.5)$ & $<0.001$ \\
\hline Education<11 yrs. & 175 & $39.6(10.4)$ & 0.158 & $38.7(11.8)$ & 0.985 & $55.5(12.4)$ & 2.26 & $42.5(09.5)$ & 2.91 \\
Education>11 yrs. & 247 & $39.4(11.0)$ & 0.875 & $39.8(12.0)$ & 0.325 & $58.3(13.1)$ & 0.024 & $45.0(07.9)$ & 0.004 \\
\hline Employed & 105 & $40.5(10.1)$ & 1.1 & $39.1(12.9)$ & 0.022 & $56.0(12.8)$ & 0.822 & $43.8(08.3)$ & 0.602 \\
Unemployed & 317 & $39.1(10.9)$ & 0.265 & $39.4(11.6)$ & 0.824 & $57.3(12.9)$ & 0.549 & $43.9(08.9)$ & 0.827 \\
\hline Income<30,000 & 247 & $39.4(10.9)$ & 0.277 & $39.2(12.2)$ & 0.331 & $56.3(13.5)$ & 1.598 & $43.1(09.1)$ & 2.339 \\
Income $>30,000$ & 175 & $39.7(10.4)$ & 0.782 & $39.6(11.5)$ & 0.74 & $58.3(11.7)$ & 0.111 & $45.1(08.1)$ & 0.02 \\
\hline No. of children<2 & 290 & $39.1(11.1)$ & 0.984 & $39.6(11.8)$ & 0.508 & $58.0(12.4)$ & 2.135 & $43.9(08.7)$ & 0.836 \\
No. of children>2 & 132 & $40.2(10.1)$ & 0.327 & $38.9(12.8)$ & 0.612 & $55.2(13.5)$ & 0.033 & $43.9(08.8)$ \\
\hline Male & 40 & $41.2(10.7)$ & 1.024 & $37.4(10.4)$ & 0.074 & $54.1(16.9)$ & 1.57 & $44.1(06.9)$ & 1.31 \\
Female & 382 & $39.3(10.8)$ & 0.307 & $39.6(11.8)$ & 0.284 & $57.4(12.5)$ & 0.053 & $44.1(08.9)$ \\
\hline Age $<30$ yrs. & 121 & $38.4(10.4)$ & 1.52 & $35.6(14.0)$ & 3.456 & $56.1(13.2)$ & 2.426 & $44.2(08.5)$ & 0.191 \\
Age $>30 y r s$ & 301 & $38.1(10.7)$ & 0.129 & $40.0(10.7)$ & $<0.001$ & $59.3(11.9)$ & 0.016 & $43.9(08.9)$ & 0.683 \\
\hline
\end{tabular}

Demographic data were amalgamated in two categories for the analysis. As shown in table 3, caregivers who were unmarried/ divorced or separated had low QOL and that was statistically significant in psychological, environmental $(\mathrm{p}=0.005)$ and social relationship domain $(\mathrm{p}<0.001)$. The mean QOL scores of caregivers who had education less than year 11 , had a low
QOL in all domains, except physical domain, and this association was statistically significant in social relationship $(\mathrm{p}=0.024)$, and environmental health domain $(\mathrm{p}=0.004)$. Caregivers whose income level was less than RS 30,000 were low in mean score of QOL, in all four domains. This association was statistically significant in environmental domain of the QOL $(\mathrm{p}<0.002)$ (Table 3).

Table 4: Association of other factors and quality of life

\begin{tabular}{|l|c|c|c|c|c|c|c|c|c|}
\hline \multicolumn{1}{|c|}{ Variable } & $\mathbf{n}$ & $\begin{array}{c}\text { Physical } \\
\text { health } \\
\text { Mean (SD) }\end{array}$ & $\begin{array}{c}\mathbf{t} \\
\mathbf{p}\end{array}$ & $\begin{array}{c}\text { Psychologic } \\
\text { al health } \\
\text { Mean (SD) }\end{array}$ & $\begin{array}{c}\mathbf{t} \\
\mathbf{p}\end{array}$ & $\begin{array}{c}\text { Social } \\
\text { health } \\
\text { Mean (SD) }\end{array}$ & $\begin{array}{c}\text { t } \\
\mathbf{p}\end{array}$ & $\begin{array}{c}\text { Environmental } \\
\text { health } \\
\text { Mean (SD) }\end{array}$ & $\begin{array}{c}\text { t } \\
\mathbf{p}\end{array}$ \\
\hline Surgery date given & 131 & $38.8(11.5)$ & 0.919 & $35.1(13.1)$ & 5.047 & $57.2(13.5)$ & 0.085 & $44.1(09.4)$ & 2.14 \\
Surgery date not given & 291 & $39.3(10.3)$ & 0.359 & $41.0(10.8)$ & $<0.001$ & $57.1(12.3)$ & 0.935 & $44.5(08.9)$ & 0.032 \\
\hline Surgery not postponed & 298 & $39.8(10.2)$ & 0.867 & $41.2(10.7)$ & 5.076 & $57.1(12.5)$ & 0.037 & $44.4(08.3)$ & 0.013 \\
Surgery postponed & 124 & $38,8(12.1)$ & 0.386 & $34.9(10.6)$ & $<0.001$ & $57.0(13.8)$ & 0.97 & $42.0(09.6)$ & 0.074 \\
\hline Acyanotic heart disease & 317 & $39.5(11.0)$ & 0.079 & $40.5(10.8)$ & 3.565 & $57.7(12.2)$ & 0.153 & $43.9(09.1)$ & 0.064 \\
Cyanotic heart disease & 105 & $39.5(11.0)$ & 0.937 & $35.8(14.1)$ & $<0.001$ & $55.4(14.5)$ & 0.122 & $43.9(07.8)$ & 0.949 \\
\hline
\end{tabular}

As shown in table 4, caregivers whose children's surgery dates were given had low mean QOL scores in all four domains. Association was statistically significant in psychological domain of the QOL $(\mathrm{p}<0.001)$ as well as the environmental domain of the QOL $(p=0.032)$. Caregivers whose children's surgery was postponed had low mean QOL scores in all domains, which was statistically significant in psychological domain of the QOL $(p<0.001)$. Caregivers of children with cyanotic heart disease had poor QOL in all four domains and that association was statistically significant in psychological domain of QOL $(\mathrm{P}<0.001)$ (Table 4).

Multiple linear regression analysis was performed to determine the associations between sociodemographic and other factors of caregivers and child level predictors with each of the domains, in a multivariate model. For each of the four domains separate analyses were conducted to determine correlates (Table 5).

The bivariate analysis of the psychological domain revealed statistically significant associations for all factors considered for the multivariate analysis.
However, the associations of psychological domain of the QOL were with religion and type of heart disease. Postponement of the surgery was judged to be non-significant following the multivariate analysis. On the other hand, surgery date given, marital status (unmarried/divorced, and separated) and age less than 30 years correlated with psychological domain of the health related QOL.

In the social relationship domain, correlates of QOL were unmarried status $(\mathrm{p}<0.005)$, and age less than 30 years $(p<0.009)$ and educational level less than year $11(\mathrm{p}<0.025)$. Nevertheless, number of children and religion, which were significant in the bivariate analysis were found to be non-significant.

Being unmarried and education level less than year 11, correlates with QOL pertaining to environmental domain in the multivariate analysis.

There was no association found with physical health domain of the QOL as per binary variable. 
Table 5: Multivariate analysis

\begin{tabular}{|c|c|c|c|c|}
\hline \multirow[t]{2}{*}{ Factor } & \multirow[t]{2}{*}{ p-value } & \multirow[t]{2}{*}{ Unadjusted beta } & \multicolumn{2}{|c|}{ 95\% confidence interva } \\
\hline & & & Lower & Upper \\
\hline \multicolumn{5}{|l|}{ Psychological domain } \\
\hline Surgery date given & 0.006 & 3.001 & 0.882 & 5.120 \\
\hline Marital status & 0.031 & -6.449 & 12.31 & 0.558 \\
\hline Age less than 30 years & 0.051 & -2.06 & 4.128 & 0.008 \\
\hline Postponement of surgery & 0.666 & 1.227 & 4.365 & 6.819 \\
\hline \multicolumn{5}{|l|}{ Social domain } \\
\hline Marital status (unmarried, separated) & 0.005 & 2.817 & 17.647 & 3.153 \\
\hline Education less than 11 years & 0.025 & -2.817 & 5.275 & 0.360 \\
\hline Age less than 30 years & 0.009 & 3.403 & 0.843 & 5.963 \\
\hline Number of children more than two & 0.332 & -1.432 & 4.341 & 1.470 \\
\hline \multicolumn{5}{|l|}{ Environmental domain } \\
\hline Marital status & 0.001 & -8.54 & 4.119 & 0.335 \\
\hline Education less than 11 years & 0.005 & 2.412 & 4.092 & 0.732 \\
\hline Surgery date given & 0.076 & 1.597 & 0.170 & 3.364 \\
\hline Income less than Rupees 30,000 & 0.237 & -1.031 & 2.742 & 0.680 \\
\hline
\end{tabular}

\section{Discussion}

As there were no published studies in Sri Lanka on QOL of a caregiver of children having CHD, this study will provide baseline information for future studies. The highest mean, namely 57.15, was recorded in the physical health domain. The mean score of the psychological domain was the lowest namely 39.38. Except for social relationship domain, all other domain values were less than $50 \%$. This finding tallies with a study done in Taiwan ${ }^{14,15}$. Mean QOL scores were lower in unmarried/widowed caregivers in all four domains. This association was statistically significant in mean QOL scores in social relationship $(p=0.005)$, psychological domain and environmental domains categories $(\mathrm{p}<0.001)$. This finding was similar to the study done in Iraq $^{15}$.

Caregivers with income less than Rupees 30,000 had low QOL in all domains and this association was statistically significant in environmental domain $(p<0.02)$. This finding was consistent with study findings of $\operatorname{Iraq}^{15}$ and cross sectional study was conducted in Alexandria, Egypt in the two main hospitals that treat children with heart disease $^{16}$. Caregivers whose children with cyanotic heart disease were poor QOL in all four domains and that association is statistically significant in psychological domain of QOL $(p<0.001)$. Similar results were presented by a study in $\operatorname{Iraq}^{15}$ and Alexandria, Egypt ${ }^{16}$

Caregivers whose children got the surgery dates had low mean QOL scores in all domains. This association was statistically significant at psychological domain of the QOL $(p<0.001)$ as well as the environmental domain of the QOL $(p<0.032)$. This finding may be due to parents getting stressed out after getting a surgery date as their child is undergoing a major surgery.
Caregivers whose children had postponement of date of surgery had low mean QOL score values. This association was statistically significant at psychological domain of the QOL $(\mathrm{p}<0.001)$.

This study was hospital based due to feasibility issues as data were collected during a two month period which consisted of an interviewer administered questionnaire, discussion with caregivers and advice and clarifications which were time consuming. The study was limited to caregivers of children who presented to the hospital for care. Those who are not been followed up in clinics regularly and those who are taking treatment in private sector were not represented in this study.

\section{Conclusions}

Caregivers of children with CHD attending cardiology clinics in LRH, Colombo and awaiting cardiac surgery are experiencing a low QOL. The QOL was associated with age of the caregiver, educational level, marital status, number of children, income, type of heart disease, and postponement of surgery. QOL had no significant association with gender, religion, employment status or presence of co-morbidities.

\section{References}

1. Mardilovich P, Hoffman R, Herman G, inventors; Hewlett Packard Development Co LP, assignee. Multilayer device with organic and inorganic dielectric material. United States patent US 8,587,093. 2013 Nov 19.

2. WHO congenital anomalies Available from:

https://www.who.int/topics/congenital_an omalies/en/ 
3. Rosano A, Botto LD, Botting B, Mastroiacovo P. Infant mortality and congenital anomalies from 1950 to 1994 : an international perspective. Journal of Epidemiology \& Community Health 2000; 54(9):660-6.

https://doi.org/10.1136/jech.54.9.660

PMCid: PMC1731756

4. Amarakoon GG, Wijayarathne HK, Kulathunga SJ, Dissanayake DH, Madurangi WH, Hirimuthugoda SN, et al. Prevalence of congenital heart disease (CHD) among children admitted to the paediatric ward of Teaching Hospital, Anuradhapura (TH/A), Sri Lanka.

5. Annual health bulletin 2015

http://www.health.gov.lk/moh_final/englis $\mathrm{h} /$ public/elfinder/files/publications/AHB/2 017/AHB\%202015.

6. Whoqol Group. The World Health Organization quality of life assessment (WHOQOL): position paper from the World Health Organization. Social Science and Medicine 1995; 41(10):14039.

https://doi.org/10.1016/02779536(95)0011 $2-\mathrm{K}$

7. Kularatna S, Whitty JA, Johnson NW, Jayasinghe R, Scuffham PA. EQ-5D-3L derived population norms for health related quality of life in Sri Lanka. PLoS One 2014; 9(11):e108434.

https://doi.org/10.1371/journal.pone.0108 434

PMid: 25365171 PMCid: PMC4217723

8. Samarasinghe D. Paediatric Cardiology in Sri Lanka: Yesterday, today and tomorrow. Sri Lanka Journal of Child Health 2014; 43(1):

https://doi.org/10.4038/sljch.v43i1.6655

9. Little Heart project proposal. http://www.dailymirror.lk/article/Little-

Hearts-LRH-
10. Lwanga SK, Lemeshow S, World Health Organization. Sample size determination in health studies: a practical manual.

11. Somasiri \& Gunawardana, (2003). Assessment of quality of life using Sinhala translation of WHOQOL-100

12. Kumarapeli VL, de A Seneviratne R, Wijeyaratne CN. Health-related quality of life and psychological distress in polycystic ovary syndrome: a hidden facet in South Asian women. British Journal of Obstetrics and Gynaecology 2011; 118(3):319-28.

https://doi.org/10.1111/j.14710528.2010.0 2799.x

PMid: 21134104

13. WHOQOL Group. (1996). WHOQOLBREF: Introduction, administration and scoring. Geneva: Mental Health programme, World Health Organization.

14. Lin JD, Hu J, Yen CF, Hsu SW, Lin LP, Loh $\mathrm{CH}$, et al. Quality of life in caregivers of children and adolescents with intellectual disabilities: use of WHOQOLBREF survey. Research in Developmental Disabilities 2009; 30(6):1448-58.

https://doi.org/10.1016/j.ridd.2009.07.005 PMid: 19660901

15. Hussein KA, Authman NR. Quality Of Life for caregivers of children with congenital heart disease in Surgical Specialty Hospital-Cardiac Center Kurdistan Region/Iraq. Kufa Journal for Nursing Sciences 2013; 3(2):148-61.

16. Arafa MA, Zaher SR, El-Dowaty AA, Moneeb DE. Quality of life among parents of children with heart disease. Health and Quality of Life Outcomes 2008; 6(1):91. https://doi.org/10.1186/1477-7525-6-91 PMid: 18980676 PMCid: PMC2590598 